\title{
Detection of helicobacter pylori in benign laryngeal lesions by polymerase chain reaction: a cross sectional study
}

\author{
Farzad Izadi ${ }^{1}$, Aslan Ahmadi ${ }^{*}$, Shadi Ghourchian², Ahmad Daneshi ${ }^{1}$, Faramarz Memari ${ }^{1}$, Ehsan Khadivi ${ }^{1}$ and \\ Shabahang Mohammadi ${ }^{1}$
}

\begin{abstract}
Background: Although Helicobacter Pylori (HP) was detected in some cases of chronic laryngitis, the results were not confirmed by polymerase chain reaction (PCR). By this time, it has not been found in laryngeal lesions by in house PCR, the most sensitive method for detecting the genome tracks. Regarding the previous results and also few numbers of studies about the presence of HP in benign laryngeal lesions, specifically by PCR, we aimed to investigate the presence of HP in benign laryngeal lesions by in-house PCR.

Methods: The samples were taken from 55 patients with benign laryngeal lesions and frozen in $-20^{\circ} \mathrm{C}$. One milliliter ( $\mathrm{ml}$ ) of lysis buffer was added to $100 \mathrm{mg}(\mathrm{mg})$ of each sample and the tube was placed in $56^{\circ} \mathrm{C}$ overnight. Then DNA extraction was carried out.

Results: To find HP DNA, in-house PCR was performed that revealed 5 positive results among 55 patients with benign laryngeal lesions. Of them, 3 were polyp, 1 was nodule and 1 was papilloma.

Conclusion: Although the number of positive results was not a lot in this study, it was in contrast with previous studies which could not find any HP tracks in benign laryngeal lesions by other methods. More studies about the prevalence of HP in benign laryngeal lesions improve judging about the effect of this infection on benign laryngeal lesions.
\end{abstract}

Keywords: Helicobacter Pylori, Laryngeal lesion, Benign, In-house PCR

\section{Background}

Helicobacter pylori (HP) is one of the risk factors of adenocarcinoma. Thus, it was categorized as a carcinogen in 1994 by the World Health Organization (WHO) $[1,2]$. Recent studies have revealed that HP can be responsible for the pathogenesis of upper gastro-esophageal tract lesions such as oral cavity. It could be found in dental plaques and secretions of the salivary glands, even when gastric involvement was not detected [3-9].

HP was detected in some cases of chronic laryngitis $(6 / 35)$ by rapid urease test [10]. However, it has not been confirmed by histology, tissue cultures, immunohistochemical methods or polymerase chain reaction

\footnotetext{
* Correspondence: aslanahmadi8931@gmail.com

${ }^{1}$ Head and Neck Research Center, Hazrat Rasoul Akram Hospital, Tehran University of Medical Sciences, Tehran, Iran

Full list of author information is available at the end of the article
}

(PCR) in benign laryngeal lesions [11,12]. Previous tests showed false positive or false negative results, regardless of the behavior of the lesion (malignant or benign) $[11,13]$.

PCR is one of the most progressive methods in molecular biology and recombinant DNA technology. The technique is used to detect smallest particles in clinical specimens with a high specificity and sensitivity [14].

The last study performed in Turkey to investigate HP in laryngeal lesions by real-time PCR and in house PCR, revealed that $58.6 \%$ of benign laryngeal lesions were infected with HP by real time PCR, but they didn't detect HP by in house PCR [15] (Figure 1). Following that article and also the absence of other previous studies about the presence of HP in benign laryngeal lesions, specifically by PCR, we aimed to investigate the presence of HP in benign laryngeal lesions by in house PCR. 


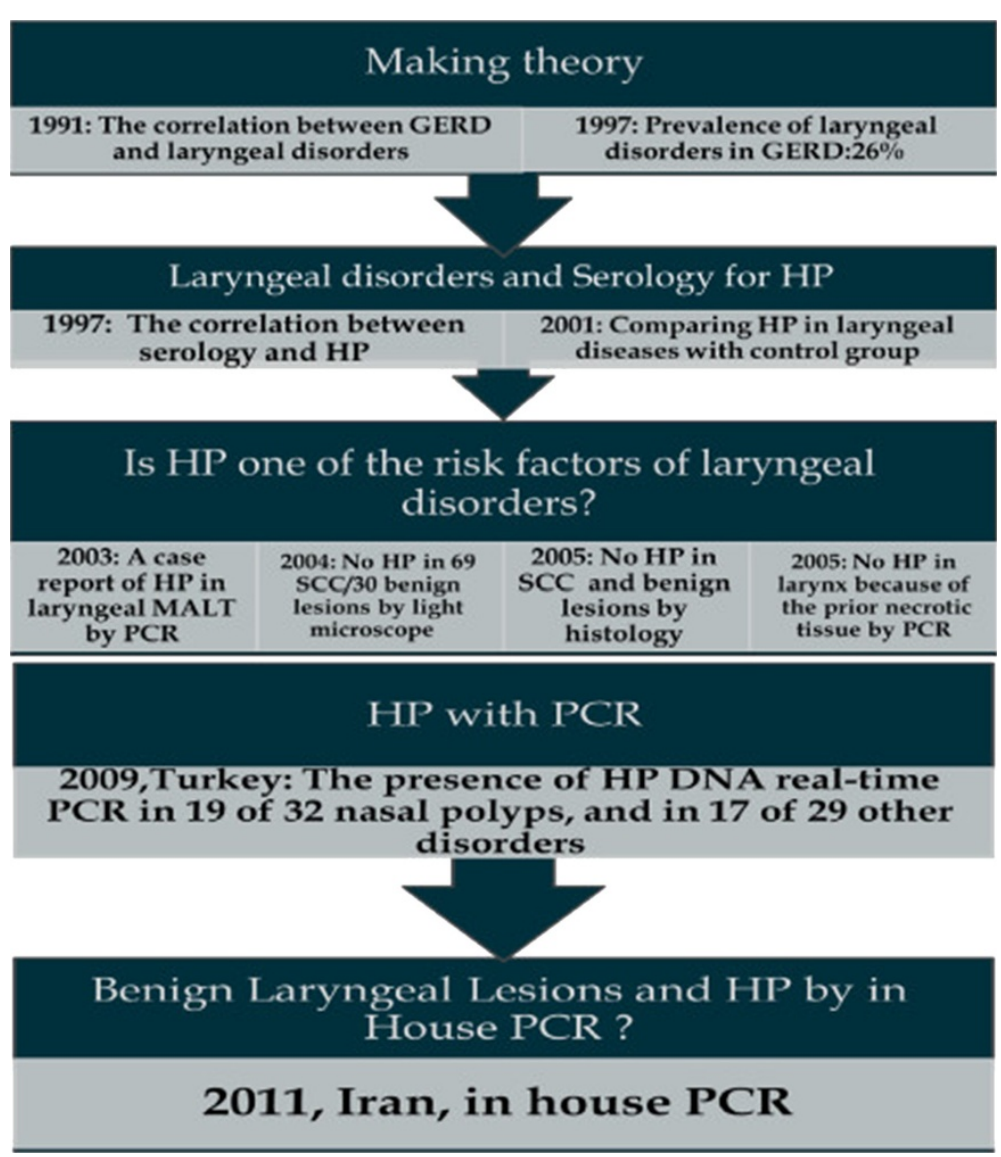

Figure 1 Different methods used to find helicobacter Pylori in laryngeal lesions, from past to now.

\section{Methods}

\section{Ethical approval}

The protocol of this study was approved by the institutional review board of the ENT research center of Rasul-e-Akram Hospital, Tehran University of Medical Sciences (TUMS). Before starting the investigation, verbal consent was established and the aim of the study was explained to all participants. Our patients did not agree to undergo endoscopy for investigation of $\mathrm{HP}$ in stomach.

To diagnose patients' disorders, the specimens were obtained from laryngeal masses. It was used for our study, if the diagnosis was confirmed as a benign laryngeal lesion. The costs were supported by the institutional board.

\section{Study design and participants}

This study was an observational cross-sectional study. Fifty five specimens with confirmed benign laryngeal lesion were evaluated for HP existence in the involved tissue. The patients with the symptoms of gastro- esophageal reflux disease (GERD) or positive history of using anti-HP drugs during the last month were excluded from the study.

Patients with GERD symptoms usually use some anti HP drugs even when the diagnosis is not confirmed with the gold standard. Regarding the ethical aspects of the study, we could not use 24-h $\mathrm{PH}$ monitoring (as the gold standard) or upper gastrointestinal tract endoscopy for the diagnosis. To make sure that the entered patients did not use any anti HP drugs, we examined the patients with GERD symptoms.

Any kinds of manipulations of intact and healthy laryngeal tissue can interfere with the vocal cords strength. In the other hand, designing the control group in our study should be based on the prevalence of the HP among intact laryngeal tissues. Regarding the illegal aspects of case-control study, we did not consider any control groups for our study. To compare the results with the frequency of HP in healthy tissues, we searched for other investigations despite the illegal entity of the 
method. No previously reported prevalence of HP in intact laryngeal tissue was found for comparison.

\section{Preparation of tissue samples}

The tissue samples $(2 \times 2.5 \mathrm{~mm}$ of the laryngeal lesion) were extracted from 55 patients with benign laryngeal lesions in Rasul-e-Akram hospital. They were transferred to media in normal saline and frozen to $-20^{\circ} \mathrm{C}$.

\section{DNA extraction}

A hundred mg of each sample was added to 1 mililiter (mL) of lysis buffer (containing of $2 \mathrm{mg}(\mathrm{mg}) / \mathrm{mL}$, proteinase $\mathrm{K}$ ) and the tube was placed in $56^{\circ} \mathrm{C}$ overnight. Then DNA extraction was carried out according to PhenolChloroform extraction method. It was kept in $-20^{\circ} \mathrm{C}$.

\section{Primers design}

Two 20-baseprimers:upstreamprimer 1520-1522nucleotide position (n.p.):5'-3' AATACACCAACGCCTCCAAG and downstream primer, 1935-1955 nucleotide position (n.p.): 5'-3' ATCTCAAGCTAACAGCCAAAA) were designed by primer 3 computer software. Analysis of primers by BLAST software showed that both primers had $100 \%$ homology with HP genome and could identify different strains. These primers targeted CagA gene of HP (full genome sequence NCBI: FJ42821501 associated number) andamplifieda496-pbfragment.

\section{In-house PCR optimization}

PCR optimization was performed using various amounts of magnesium chloride 2 ( $\mathrm{MgCl} 2)$, dNTPs, primers and different annealing temperatures using several dilution of template DNA. To amplify the fragments in each sample, $10 \mu \mathrm{l}$ $(1 \mu \mathrm{g})$ extracted DNA was added to a reaction mixture containing dNTPs, $200 \mu \mathrm{M} ; 10 \mathrm{pmol}$ of each primer, $\mathrm{MgCl} 2$ $1 \mu \mathrm{l} ; 50 \mathrm{mM}$ and Taq DNA polymerase, 1U; (Ferments, Lithuania) in a total reaction volume of $25 \mu \mathrm{l}$. The samples were amplified for 40 cycles in an oil free automated thermal, verity of $A B I$, USA consisting of first denaturation at $94^{\circ} \mathrm{C}$ for $5 \mathrm{~min}$, followed by cycles of denaturation at $94^{\circ} \mathrm{C}$ for $30 \mathrm{~s}$, annealed at $50^{\circ} \mathrm{C}$ for $30 \mathrm{~s}$ and extension at $72^{\circ} \mathrm{C}$ for $40 \mathrm{~s}$, with a final incubation at $72^{\circ} \mathrm{C}$ for $5 \mathrm{~min}$. The PCR products were separated on $3 \%$ agarose gel and stained with $3 \mu \mathrm{g} / \mathrm{ml}$ ethidium bromide solution. The stained gel was photo grated using gel documentation instrument with a digital imaging camera system (UV tech, Germany).

\section{Check list and analysis}

To gather patients' data, the drug history specially any anti HP drugs, and the results of their own biopsies and in-house PCR, were entered to a self-designed check list. We used SPSS software version17 for analysis.

To describe the prevalence of different qualitative variables descriptive indexes were used. Also mean and standard deviation (SD) were used to present quantitative variables.

\section{Results}

Of 55 patients, 33 (60\%) were male. The mean age was $22 \pm 10.57$ years old with the range of 5 to 55 years of age. None of the patients used any drugs during the last month. None of them had any symptoms of GERD. Also the patients didn't undergo any upper gastroesophageal tract manipulations, previously. Polyp was the most prevalent disorder among our patients $(38.18 \%)$. The prevalence of positive results among each group of patients is shown in Table 1.

In-house PCR of HP DNA revealed positive results in 5 of 55 patients $(9.09 \%)$. Fifty five specimens included 21 polyps (38.18 \%), 14 nodules (25.45 \%) and 20 cases of papillomatosis $(36.36 \%)$. Of the specimens which were positive for HP, 3 (60\%) were polyp, 1 (20\%) was nodule and $1(20 \%)$ was papilloma.

\section{Discussion}

HP was identified as a risk factor for lots of malignancies. About half of the persons around the world are infected by HP $[16,17]$.

If $\mathrm{HP}$ involves the parts surrounding the lower esophageal sphincter, the probability of GERD increases. GERD increases the risk of malignancies in upper parts of gastro-esophageal tract. Of the organs located in the tract, larynx is prone to laryngeal carcinoma $[18,19]$. Also HP can be one of the risk factors of nasal polyp by causing chronic inflammation [11,20-24].

Among the studies investigated the relationships between GERD and laryngeal injuries, Koufman showed that $40-60 \%$ of patients with voice disorders were presented by reflux symptoms [25]. Batch found the prevalence of $63 \%$ of esophagitis in patients with laryngitis [26]. Paterson detected GERD in $26 \%$ of patients with laryngeal disorders [27]. Because HP infection in stomach and so its distribution to esophagus was prevalent among the Iranian people [28], we didn't investigate HP in esophagus in our study. In addition, our patients didn't agree to undergo endoscopy. But HP infection was not usual in larynx.

In 2004, Ahmet Kizilay, et al. refused the presence of HP in their specimens from 69 cases with squamus cell carcinoma (SCC) and 30 patients with non-neoplastic

Table 1 The prevalence of positive results among 55 patients with benign laryngeal lesions

\begin{tabular}{lll}
\hline Polyp: $21(38.18 \%)$ & Nodule: 14 & Papilomatosis: 20 \\
& $(25.45 \%)$ & $(36.36 \%)$ \\
\hline Positive results: & Positive results: & Positive results: \\
$3(14.28 \%)$ & $1(7.14 \%)$ & $1(5 \%)$ \\
\hline
\end{tabular}


diseases of larynx by using light microscope [29]. Also in the same year, Nihat Akbayir, et al. didn't find HP in the specimens from patients with laryngeal SCC (50) by means of histology [11].

Furthermore, the presence of HP in malignant laryngeal lesions (by using immunohistochemical methods and light microscope) was compared with the presence of HP in benign laryngeal lesions (by histopathology) [11].

Prior to invasive methods, some investigators evaluated the serologic changes in HP infected patients and the prevalence of laryngeal cancer. Their results were in conflict. Some studies revealed significant differences between the prevalence of HP in patients with laryngeal cancer and the control group [29-31]. The results of the correlation between HP existence and laryngeal tumors were different [32]. In the other hand, some studies revealed that HP was not detected in malignant laryngeal lesions by immunohistochemical methods but there were some positive results by histological evaluations. Also they did not find HP tracks in specimens with benign laryngeal lesions in that study. The authors supposed that spontaneous eradication of HP in the malignant tissues which are surrounded by atrophic areas is the reason of their findings but this theory could not explain the absence of HP in non-atrophic tissues [11]. Some articles revealed a high prevalence of HP in patients with squamous cell carcinoma (SCC) of the larynx by serology $[30,33,34]$.

According to our search, except a case report in which the diagnosis of HP was confirmed by PCR in a patient with laryngeal MALT lymphoma [15,35], there was no specific method used for confirming HP in laryngeal cancers without false positive result [36]. PCR was used in a study in Turkey that studied 32 patients with nasal polyps, 9 patients with SCC, 5 patients with chronic inflammation, 8 cases with laryngeal nodules, 2 cases with laryngeal papillomatosis, 2 with laryngeal polyps, one with laryngeal web, one with laryngeal dysplasia, and one with laryngeal hemangioma. By using real-time PCR, they found HP DNA in 19 of 32 nasal polyps, and in 17 of 29 laryngeal samples with other disorders [15]. Also cag A of HP was found in $30 \%$ of tonsil and adenoid tissues by real-time PCR and in $24.6 \%$ of the same tissues by in house PCR $[24,37]$ (Table 1).

By our investigation, according to the high specificity and sensitivity of in-house PCR, we found HP in the patients with benign laryngeal lesions including polyp, nodule and papilloma.

Although the number of cases in this study was more than other previous studies, most of our patients could not be entered following the usage of anti HP drugs. Most of our patients with papiloma used omeprazole (as a self therapy) to relieve their upper gastrointestinal symptoms. Thus we missed lots of our cases for this study due to the high prevalence of anti HP drugs consumers among our patients. We excluded patients with GERD symptoms, but because of logical aspects, we could not use 24-h $\mathrm{PH}$ monitoring or endoscopy to confirm the diagnosis.

In our study the samples should be sent for pathology and genetic studies. Some of the excised lesions were too small to be divided to two parts and thus we could not investigate HP genomes in some small species.

\section{Conclusion}

Although the number of our positive results was not a lot, it was in contrast with previous studies which could not find any HP tracks in benign laryngeal lesions by other methods. More studies about the prevalence of HP in benign laryngeal lesions improve judging about the casualty of this infection in benign laryngeal lesions.

\section{Abbreviations}

$\mathrm{HP}$, helicobacter; PCR, polymerase chain reaction; SD, standard deviation.

\section{Competing interests}

The authors declare that they have no competing interests.

\section{Author details}

${ }^{1}$ Head and Neck Research Center, Hazrat Rasoul Akram Hospital, Tehran University of Medical Sciences, Tehran, Iran. ${ }^{2}$ Medical student, Students' Scientific Research Center (SSRC) of Tehran University of Medical Sciences, Tehran University of Medical Sciences, Tehran, Iran.

\section{Authors' contributions}

FI, AD, SM, FM, AA: study concept and design; acquisition, doing the surgeries, revising the article. EK: Laboratory studies, doing PCR, revising the article. SG: Acquisition, analysis and interpretation of data, writing the manuscript, critical drafting of manuscript and revision of manuscript. All authors read and approved the final manuscript.

Received: 28 September 2011 Accepted: 19 April 2012

Published: 19 April 2012

\section{References}

1. André AR, Ferreira MV, Mota RM, Ferrasi AC, Pardini MI, Rabenhorst SH: Gastric adenocarcinoma and Helicobacter pylori: correlation with p53 mutation and p27 immunoexpression. Cancer Epidemiol 2010, 34(5):618625.

2. Fukase K, Kato M, Kikuchi S, Inoue K, Uemura N, Okamoto S, Terao S, Amagai K, Hayashi S, Asaka M, Japan Gast Study Group: Effect of eradication of Helicobacter pylori on incidence of metachronous gastric carcinoma after endoscopic resection of early gastric cancer: an open-label, randomised controlled trial. Lancet 2008, 9636:392-397.

3. Dore-Davin C, Heitz M, Yang H, Herranz M, Blum AL, Corthesy-Theulaz I: Helicobacter pylori in the oral cavity reflects handling of contaminants but not gastric infection. Digestion 1999, 60:196-202.

4. Nishimura M, Miyajima S, Okada N: Salivary gland MALT lymphoma associated with Helicobacter pylori infection in a patient with Sjögren's Syndrome. J Dermatol 2000, 27(7):450-452.

5. Song Q, Lange T, Spahr A, Adler G, Bode G: Characteristic distribution pattern of helicobacter pylori in dental plaque and saliva detected with nested PCR. J Med Microbiol 2000, 49:349-353.

6. Okuda K, Ishihara K, Miura T, Katakura A, Noma H, Ebihara Y: Helicobacter pylori may have only a transient presence in the oral cavity and on the surface of oral cancer. Microbiol Immunol 2000, 44:385-388.

7. Wichelhaus A, Brauchli L, Song Q, Adler G, Bode G: Prevalence of Helicobacter pylori in the adolescent oral cavity: dependence on 
orthodontic therapy, oral flora and hygiene. J Orofac Orthop 2011, 72 (3):187-195.

8. Eskandari A, Mahmoudpour A, Abolfazli N, Lafzi A: Detection of Helicobacter pylori using PCR in dental plaque of patients with and without gastritis. Med Oral Patol Oral Cir Bucal. 2010, 15(1):28-31.

9. Goosen C, Theron J, Ntsala M, Maree FF, Olckers A, Botha SJ, Lastovica AJ, van der Merwe SW: Evaluation of a novel heminested PCR assay based on the phosphoglucosamine mutase gene for detection of Helicobacter pylori in saliva and dental plaque. J Clin Microbiol 2002, 40(1):205-209.

10. Borkowski G, Sudhoff H, Koslowski F, Hackstedt G, Radu HJ, Luckhaupt H: A possible role of helicobacter pylori infection in the etiology of chronic laryngitis. Eur Arch Otorhinolaryngol 1997, 254:481-482.

11. Akbayir N, Basak T, Seven $\mathrm{H}$, et al: Investigation of Helicobacter pylori colonization in laryngeal neoplasia. Eur Arch Otorhinolaryngol 2005, 262:170-172.

12. Jaspersen D, Weber R, Diehl KL, Kind M, Arps H, Draf W: Ist die chronische Laryngitis Helicobacter-pylori -assoziiert? Ergebnisse einer prospektiven Studie. Z Gastroenterol 1998, 36:369-372.

13. Megraud F, Lehours P: Helicobacter pylori detection and antimicrobial susceptibility testing. Clin Microbiol Rev 2007, 20:280-322.

14. Linke S, Lenz J, Gemein S, Exner M, Gebel J: Detection of Helicobacter pylori in biofilms by real-time PCR. Int J Hyg Environ Health 2010, 213 (3):176-182.

15. Mustafa Ozyurt PhD, Atila Gungor MD, Koray Ergunay MD, PhD, Engin Cekin MD, Evren Erkul MD, Tuncer Haznedaroglu MD . Real-time PCR detection of Helicobacter pylori and virulence-associated cagA in nasal polyps and laryngeal disorders. Otolaryngol Head Neck Surg 2009, 141: 131-135

16. Parsonnet J, Hansen S, Rodriguez L, Gelb AB, Warnke RA, Jellum E, Orentreich N, Vogelman JH, Freidman GD: Helicobacter pylori infection and gastric lymphoma. N Engl J Med 1994, 330:1267-1271.

17. Us D, Hascelik G: Seroprevalence of Helicobacter pylori infection in an asymptomatic Turkish population. J Infect 1998, 37:148-150.

18. Ulualp SO, Toohill RJ: Laryngopharyngeal reflux: state of art diagnosis and treatment. Otolaryngol Clin North Am 2000, 33:785-802

19. Harrill WC, Stasney CR, Donovan DT: Laryngopharyngeal reflux: a possible risk factor in laryngeal and hypopharyngeal carcinoma. Otolaryngol Head Neck Surg 1999, 120:598-601.

20. Kusters JG, van Vliet AHM, Kuipers EJ: Pathogenesis of Helicobacter pylori infection. Clin Microbiol Rev 2006, 19:449-490.

21. Ozdek A, Cirak MY, Samim E, et al: A possible role of Helicobacter pylori in chronic rhinosinusitis: a preliminary report. Laryngoscope 2003, 113:679682.

22. Titiz A, Ozcakir O, Ceyhan S, et al: The presence of Helicobacter pylori in the larynx pathologies. Auris Nasus Larynx 2008, 35:534-538.

23. Koc C, Arikan OK, Atasoy P, et al: Prevalence of Helicobacter pylori in patients with nasal polyps: a preliminary report. Laryngoscope 2004, 114:1941-1944.

24. Cirak MY, Ozdek A, Yilmaz D, et al: Detection of Helicobacter pylori and its CagA gene in tonsil and adenoid tissues by PCR. Arch Otolaryngol Head Neck Surg 2003, 129:1225-1229

25. Koufman JA: The otolaryngologic manifestations of gastroesophageal reflux disease (GERD): a clinical investigation of 225patients using ambulatory 24-hour $\mathrm{pH}$ monitoring and an experimental investigation of the role of acid and pepsin in the development laryngeal injury. Laryngoscope 1991, 101:1-78.

26. Batch AJG: Globus pharyngeus (Part 1). J Laryngol Otol 1998, 102:152-158

27. Paterson WG: Extraesophageal complications of gastroesophageal reflux disease. Can J Gastroenterol 1997, 11:45B-50B.

28. Salehi Z, Jelodar MH, Rassa M, Ahaki M, Mollasalehi H, Mashayekhi F: Helicobacter pylori cagA status and peptic ulcer disease in Iran. Dig Dis Sci 2009, 54(3):608-613.

29. Kizilay A, Saydam L, Aydin A: M. Tayyar Kalcioglu, Orhan Ozturan, N. Engin Aydin. Histopathologic Examination for Helicobacter pylori as a Possible Etiopathogenic Factor in Laryngeal Carcinoma. Chemotherapy 2006, 52:80-82.

30. Aygenc E, Selcuk A, Celikkanat S, Ozbek C, Ozdem C: The role of helicobacter pylori infection in the cause of squamous cell carcinoma of the larynx. Otolaryngol Head Neck Surgery 2001, 125:520-521.

31. Rubin JS, Benjamin E, Prior A, Lavy J: The prevalence of helicobacter pylori infection in malignant and premalignant conditions of the head and neck. J Laryngol Otol 2003, 117:118-121.
32. Masoud N, Manouchehr K, Najmeh D, Monireh H: Lack of association between Helicobacter pylori and laryngeal carcinoma. Asian Pac J Cancer Prev Jan-Mar 2008, 9(1):81-82

33. Grandis JR, Perez-Perez GI, Yu VL, Johnson JT, Blaser MJ: Lack of serologic evidence for helicobacter pylori infection in head and neck cancer. Head Neck 1997, 19:216-218.

34. Said, Rosaida Mohd; Cheah, Phaik-Leng; Chin, Sow-Chan; Goh, Khean-Lee . Evaluation of a new biopsy urease test: Pronto Dry, for the diagnosis of Helicobacter pylori infection. Eur J Gastroenterol Hepatol 2004,16(2): 195199

35. Caletti G, Caletti G, Togliani T, Fusaroli $P$, et al: Consecutive regression of concurrent laryngeal and gastric MALT lymphoma after antiHelicobacter pylori therapy. Gastroenterol 2003, 124:537-543.

36. Akbayir N, Basak T, Seven H, Sungun A, Erdem L: Investigation of Helicobacter pylori colonization in laryngeal neoplasia. Eur Arch Otorhinolaryngol 2005, 262:170-172.

37. Bulut $Y$, Agacayak A, Karlidag T, et al: Association of cagA + Helicobacter pylori with adenotonsillar hypertrophy. Tohoku J Exp Med 2006, 209:229233.

doi:10.1186/1750-9378-7-10

Cite this article as: Izadi et al: Detection of helicobacter pylori in benign laryngeal lesions by polymerase chain reaction: a cross sectional study. Infectious Agents and Cancer 2012 7:10.

\section{Submit your next manuscript to BioMed Central and take full advantage of:}

- Convenient online submission

- Thorough peer review

- No space constraints or color figure charges

- Immediate publication on acceptance

- Inclusion in PubMed, CAS, Scopus and Google Scholar

- Research which is freely available for redistribution 